\title{
Hydroethanolic Extract of Eribroma oblongum (Malvaceae) Stem Bark Prevents Hypertension, Oxidative Stress and Dyslipidemia in L-NAME Induced Hypertension in Wistar Rats
}

\author{
Tsague Marthe Valentine ${ }^{1,2}$, Fokunang N. Charles ${ }^{1, *}$, Tembe Achick Estella ${ }^{1}$, \\ Mvondo Anne Mauricette ${ }^{1}$, Afane Ela Anatole ${ }^{1}$, Oben E. Julius ${ }^{4}$, Ngadjui Tchaleu Bonaventure ${ }^{1,4}$, \\ Ntchapda Fidèle $^{2}$, Sokeng Dongmo Sélestin ${ }^{2}$, Nyangono Biyegue Christine Fernande ${ }^{6}$, \\ Dimo Théophile ${ }^{4}$, Ze Minkande Jacqueline ${ }^{1}$ \\ ${ }^{1}$ Faculty of Medicine and Biomedical Sciences, University of Yaoundé I, Yaoundé, Cameroon \\ ${ }^{2}$ Faculty of Sciences, Faculty of Science, Department of Biological Sciences, Ngaoundéré, Ngaoundéré-Cameroon \\ ${ }^{3}$ Department of Biomedical Sciences, University of Ngaoundere, Ngaoundere, Cameroon \\ ${ }^{4}$ Faculty of Sciences, University of Yaounde 1, Yaounde, Cameroon. \\ ${ }^{5}$ Higher Teachers' Training College, Faculty of Sciences, University of Yaoundé 1, Yaoundé-Cameroon, Cameroon \\ ${ }^{6}$ Higher Teacher's Technical Training School, University of Douala, Douala, Cameroon
}

Email address:

charlesfokunang@yahoo.co.uk (F. N. Charles)

${ }^{*}$ Corresponding author

To cite this article:

Tsague Marthe Valentine, Fokunang N. Charles, Tembe Achick Estella, Mvondo Anne Mauricette, Afane Ela Anatole, Oben E. Julius, Ngadjui Tchaleu Bonaventure, Ntchapda Fidèle, Sokeng Dongmo Sélestin, Nyangono Biyegue Christine Fernande, Dimo Théophile, Ze Minkande Jacqueline. Hydroethanolic Extract of Eribroma oblongum (Malvaceae) Stem Bark Prevents Hypertension, Oxidative Stress and Dyslipidemia in L-NAME Induced Hypertension in Wistar Rats. Journal of Diseases and Medicinal Plants. Vol. 2, No. 4, 2016, pp. 43-50. doi: $10.11648 /$ j.jdmp.20160204.11

Received: April 22, 2016; Accepted: May 17, 2016; Published: June 16, 2016

\begin{abstract}
Introduction: Eribroma oblongum (Malvaceae) stem bark is used in Cameroonian ethnomedicine to treat various metabolic illnesses including cardiovascular diseases. The present study was designed to investigate the mechanisms of hypotensive effects of hydroethanolic extract of Eribroma oblongum and its cardioprotective effects after a subchronic treatment. Study Design: This was a prospective cross-sectional analytical study Methodology: Preventive effects were studied after oral administration of hydroethanolic extract of Eribroma oblongum (HEEO) (100 mg/kg body weight/day) or captopril $(25 \mathrm{mg} / \mathrm{kg}$ body weight/day) simultaneously with L-NAME $(40 \mathrm{mg} / \mathrm{kg}$ body weight/ day) in rats for 28 days. Body weight and food intake were measured after 5 days. At the end of treatment, blood pressure and heart rate were recorded. Aorta, heart, liver and kidneys were weighted. Reduced nitrite, superoxide dismutase, catalase, gluthatione, Malondialdehyde and lipid profile were measured. Results: The extract prevented L-NAME hypertension and improved food intake and body weight of rats. HEEO improved lipid profile and antioxidant status. L-NAME caused a significant $(\mathrm{P}<0.001)$ increase in the levels of serum transaminase relative to the normal. L-NAME treated rats had markedly decreased catalase (CAT), superoxide dismutase (SOD), nitrite $\left(\mathrm{NO}_{2}^{-}\right)$and reduced glutathione (GSH) levels in the tissue. Also, L-NAME caused a significant $(\mathrm{P}<0.001)$ induction of lipid peroxidation (MDA) in the animals tissue relative to the normal range. Administration of HEEO with L- NAME caused significant $(\mathrm{P}<0.001)$ inhibition of MDA relative to LNHR and augmented tissue antioxidant indices. Conclusion: The hydroethanolic stem bark extract of Eribroma oblongum showed a promising potential cardioprotective effect in L-NAME induced hypertension. This effect could be due at least in part by improving endothelial function, lipid profile and oxidative status. These findings justify the traditional use of HEEO as treatment in cardiovascular disorders and serve as a promising traditional pharmacopoeia for the development of new chemical entity in the phytomedicine development platform.
\end{abstract}


Keywords: Eribroma oblongum, L-NAME, Blood Pressure, NO, Antihypertensive and Antioxidant Activities, Wistar Rat

\section{Introduction}

Previous study showed that the hydroethanolic extract of Eribroma oblongum possesses antihypertensive and antiatherogenic properties in a model that atherogenic diet induced hypertension in Wistar rats. Essential hypertension accounts for approximately $90 \%$ to $95 \%$ of patients diagnosed with hypertension [1] and it is mainly caused by endothelial dysfunction. Endothelial dysfunction itself results from NO deficiency. In fact, it has been found that vascular endothelium of hypertensive patients produces less nitric oxide, a key regulator of cardiovascular system and metabolic homeostasis [2]. The inhibition of NO production by L-arginine analogue like Nw Nitro-L- arginine methylester (L-NAME) therefore results in arterial hypertension, dyslipidemia and histological damages. L-NAME-induced hypertension is thus a suitable model to study the cardiovascular effects of new active substances. Eribroma oblongum stem bark is widely used in Cameroon for treatment various metabolic illness such as hypertension. Cardiovascular disease is the leading cause of death and a major cause of disability not only in the United States but also worldwide [3]. Also known as the "silent killer", hypertension is estimated to cause $4.5 \%$ of current global disease burden and is as prevalent in many developing countries, as in the developed world [4].There are controllable factors such as poor diet, obesity, excessive consumption of alcohol or salt, stress and physical inactivity, and non-controllable factors such as age and heredity. Treatments of hypertension are usually diuretics, beta blockers, alpha blockers, calcium channel blockers, angiotensin II receptors inhibitors, inhibitors of angiotensinconverting enzyme and mimetic nitric oxide. High blood pressure is particularly dangerous because it usually remains silent, which greatly increases the risk of complications. Patients balk the necessity of treatment in the absence of obvious symptoms, and most importantly, because of the high cost of drugs in modern medicine. Therefore in developing countries such as Cameroon, people resort to traditional medicine by phytotherapy to solve their health problems. They are encouraged by the affordability, efficiency and availability of this medicine [5]. However, scientific investigations are necessary to confirm these therapeutic claims and to regulate the use of these herbal drugs by populations. Eribroma oblongum (Malvaceae) is a tree of about $15 \mathrm{~m}$ high found in Central Africa. It is widely used in African traditional medicine to treat various metabolic illnesses including cardiovascular diseases. In Cameroon, decoction of E. oblongum dried stem bark is used by traditional healers of Centre Region, for the management of cardiovascular diseases, especially hypertension in combination with other plants [6]. Phytochemical investigations have shown the presence phytochemical analysis revealed the presence of reduced sugar, flavonoides, tannins, phenols and saponins. Terpenoides, alkaloids, lipids, steroid cardiac glycosides, anthraquinones, and triterpenes were absent [6]. The present investigation was undertaken to examine the antihypertensive activities of the stem bark hydroethanolic extract of E. oblongum in L-NAME-induced hypertensive rats (LNHR). For that purpose, we analyzed the effect of subchronic administration of the extract on blood pressure and heart rate, on oxidative stress and lipid profile, transaminase and creatinine induced by Nw-Nitro-L-arginine Methyl ester hydrochloride (L-NAME) by oral administration.

\section{Material and Methods}

\subsection{Experimental Design}

This study was performed on male Wistar rats from the Laboratory of Animal Physiology in the Department of Physiology, Faculty of Sciences, University of Yaoundé ICameroon. Male albino Wistar rats of 10-12 weeks of age, weighting 200-250 g were selected for these experiences. The animals were kept in a room maintained under environmentally controlled condition of temperature $23-25^{\circ} \mathrm{C}$ and $12 \mathrm{~h}$ light/dark cycle, with free access to tap water ad libitum and standard commercial diet. L-NAME induced hypertensive rats (LNHR) were used. To obtain LNHR, LNAME was orally administrated to normotensive rats (NTR) for 28 days. Body weight and food intake were measured every 5 days until the end of experimentation. Then, rats with a systolic blood pressure higher than $140 \mathrm{mmHg}$ were considered as hypertensive. The experimental protocol and the maintenance of the experimental animals was done in accordance with the standard ethical guidelines for laboratory animal use and care as described in the European Community guidelines; EEC Directive $86 / 609 / \mathrm{EEC}$, of the 24th November 1986 [7].

\subsection{Plant Material}

Fresh stem bark of Eribroma oblongum were collected at Eseka, Centre province of Cameroon, in August 2013. The plant material was identified at the National Herbarium (HNC) of Yaoundé-Cameroon where a voucher specimen $\mathrm{N}^{\circ} 27489$ SRFCam has been deposited [6].

\subsection{Drying and Preparation of the Extract of HEEO}

Before drying could start, the plants were washed to remove sand and dust particles. The stem bark was separated from the rest of the plant and dried separately under shade in an airy condition. The stem bark was air dried at room temperature and ground into a powder. The extraction was done by using cold maceration process. The grounded plant material $(2 \mathrm{~kg})$ was soaked in $5 \mathrm{~L}$ of water-ethanol mixture 
(50:50) for 48 hours at room temperature. After two days of occasional shaking, the whole material was filtered using a funnel and filter paper and then kept in a flask. Removal of the solvent from the obtained extract under reduced pressure using a rotary evaporator. The crude extract was then airdried to obtain a solid mass with a yield of $25 \%$. The extracts were then kept separately in small bottles and put in the fridge for later use [6].

\subsection{Animal Studies}

\subsubsection{Animal Regulatory Issues}

Healthy male albino Wistar rats (body weight 150-250 g) are preferred for the experiment according to the ICH guidelines. The experimental protocol and the maintenance of the experimental animals was done in accordance with the regulations of the OEDD guide since in Cameroon the ethics committee focuses only on clinical studies. The animal experiment protocols was carried out in accordance with the guidelines of the $\mathrm{ICH}$ on preclinical pharmaceutical testing in mouse..Male albino Wistar rats of 12 weeks old weighting 180-250 g were used. The animals were maintained on a $12 \mathrm{~h}$ light/dark cycle, with free access to water and standard laboratory diet. Normotensive rats (NTR) were used to evaluate hypotensive effect in the ethyl acetate extract and compounds on arterial blood pressure, heart rate and its mechanisms of action.

\subsubsection{Animal Selection}

Male albino Wistar rats of 12 weeks old weighting 190$250 \mathrm{~g}$ were used. The animals were maintained on a $12 \mathrm{~h}$ light/dark cycle, with free access to water and standard Laboratory diet. Normotensive rats (NTR) were used to evaluate effects of the plant extract on arterial blood pressure, heart rate and its mechanisms of action. To determine the antihypertensive activity mechanism of Eribroma oblongum, atherogenic diet induced- hypertensive rats (ADHR) were used. To obtain ADHR, NTR were fed by

atherogenic diet for 45 days. Body weight and food intake were of study. The feeding for 45 days was done to get a steady trend that can be validated and also to be able to assess the effect of possible organ toxicity which was an aspect of interest of the study to us. Then, rats with a systolic blood pressure higher than $140 \mathrm{mmHg}$ were considered as hypertensive.

\subsubsection{Subchronic Effects of Hydroethanolic Extract of Eribroma Oblongum in L-NAME Induced Hypertension}

Normotensive rats were randomly divided into four groups. The first group made of 5 rats served as control and received distilled water; the second group made of 5 rats received only L-NAME (40 $\mathrm{mg} / \mathrm{kg}$ body weight/day); the third group constituted of 5 rats received concomitantly LNAME (40 mg/kg body weight/day) and captopril $(25 \mathrm{mg} / \mathrm{kg}$ body weight/day) and the last group made of 5 rats received concomitantly L-NAME (40 mg/kg body weight/day) and plant extract $(100 \mathrm{mg} / \mathrm{kg}$ body weight/day). All these products were dissolved in water and given daily per os to the animals for a period of 28 days. During this period, food consumption and body weight were noted. At the end of treatment, the rats were fasted for $12 \mathrm{~h}$ before the rats were anesthetized using an intraperitoneal injection of urethane $(1.5 \mathrm{~g} / \mathrm{kg}$ body weight/day). The trachea was exposed and cannulated to facilitate spontaneous respiration. A polyethylene catheter was inserted into the rat carotid artery. This catheter was linked to the transducer connected to the recorder hemodynamic signal was transferred to an acquisition system (Biopac Student Lab MP type 35) coupled with a computer. Another catheter was inserted into the femoral vein and a bolus injection of $10 \%$ heparin $(0.1$ $\mathrm{mL} / 100 \mathrm{~g}$ body weight) was immediately administered. The animals were allowed to stabilize for at least 30 minutes [8; 9]. The blood was collected from carotid arterial of the animals into dried tubes. Serum was prepared by centrifugation at $1000 \mathrm{~g}$ for 15 minutes. The clear supernatant was used for the estimation of serum lipid profile, hepatic and renal functions.

\subsection{Preparation of Tissues}

Aorta, heart, liver and kidneys were dissected out, washed in ice-cold $9 \% \mathrm{NaCl}$ solution, dried and weighed. All these tissues and the remaining parts of liver homogenized. The Mc Even solution $\left(\mathrm{mM} \mathrm{NaCl}, 147 ; \mathrm{CaCl}_{2}, 2.6 ; \mathrm{CO}_{3} \mathrm{HNa}\right.$ 11.6; D-glucose, 11; KCl, 5.6; $\mathrm{NaH}_{2} \mathrm{PO}_{4}, 0.66 ; \mathrm{MgCl}_{2}, 0.24$ ) was used for aorta $(10 \% \mathrm{~m} / \mathrm{v})$, heart $(20 \% \mathrm{~m} / \mathrm{v})$ and Tris- $\mathrm{HCl}$ $50 \mathrm{mM}$ buffer solution was used for liver and kidneys $(20 \%$ $\mathrm{m} / \mathrm{v}$ ). The tissues were centrifuged at $15,000 \mathrm{~g}$ for 20 minutes to obtain post-mitochondrial supernatant fraction. All procedures were carried out at temperature of $-4^{\circ} \mathrm{C}[6]$.

\subsection{Biochemical Analysis}

\subsubsection{Oxidative Stress Markers}

Tissue levels of Superoxide dismutase (SOD) activity was assayed according the method described by Misra and Fridovich (1972) [10], catalase (CAT) by sinha (1972) [11], reduced glutathione (GSH) by Ellman (1959) [12]; nitrites $\left(\mathrm{NO}_{2}{ }^{-}\right)$assay was performed using the methods of Ikeda et al., 2003 [13] and malondylaldehyde (MDA) was assayed according to Wilbur et al., 1949 [14].

\subsubsection{Lipid profile Assays}

Blood samples were collected in dried tubes and the serum was obtained by centrifugation at $1000 \mathrm{~g}$ during 15 minutes at $-4^{\circ} \mathrm{C}$ for serum activities. The lipoproteins were measured using the enzymatic colorimetric method. Samples were assayed for total cholesterol HDL-cholesterol and triglycerides by using the kits (Fortress diagnostics). The low-density lipoprotein (LDL) was calculated using the formula by Friedewald et al., 1972 [15]. All these parameters were determined by measurement of the optical density of the reaction products at the corresponding wavelengths with spectrophotometer (Genesys 20, Thermo Fisher Scientific, Waltham, MA, USA). 


\subsubsection{Determination the Atherogenic Index And the Protection Percentage}

$$
\text { Atherogenic index } 1=\frac{\text { Total }- \text { Cholesterol }}{H D L-\text { Cholesterol }}
$$

or

$$
\text { Atherogenic index } 2=\frac{\mathrm{LDL}-\text { Cholesterol }}{\mathrm{HDL}-\text { Cholesterol }}
$$

* Protection (\%)

$=\frac{\text { Atherogenic index of control }- \text { Atherogenic index group treated }}{}$

\subsection{Statistical Analysis}

The results were expressed as means \pm SEM and analyzed with Graph Pad Instat Software. The comparisons within the experimental groups were made using one way analysis of variance (ANOVA) followed by Dunnett as post hoc test. P values less than 0.05 were considered significant

\section{Results}

\subsection{Subchronic effects of E. Oblongum}

\subsubsection{Body Weight}

As shown in table 1, the body weight increased in all groups during the treatment, however this increase was low in test groups compared to normal group. Rats treated with L-NAME were showed the lowest increasing of body weight which was significant $(\mathrm{P}<0.01)$ compared to normal group. Thus the percentages of growth were 66.32, 52.65 and $57.71 \%$ respectively for L-NAME, captopril, extract at the doses of $100 \mathrm{mg} / \mathrm{kg}$ body weight/day. In rats treated with HEEO and captopril, the increase of body weight was significantly $(\mathrm{P}<0.01)$ reduced from the fifteenth day compared to normal group.

Table 1. Effects of E. oblongum on body weight of L-NAME hypertensive rats after 4 weeks of treatment.

\begin{tabular}{lllllll}
\hline Body weight variations \% & & & & & \\
\hline Group & day-5 & day-10 & day-15 & day-20 & day-25 & day-28 \\
\hline Normal & $7.9 \pm 0.23$ & $9.06 \pm 1.28$ & $12.5 \pm 2.8$ & $16.8 \pm 3$ & $18.44 \pm 3.2$ & $19.7 \pm 5.54$ \\
L-NAME & $3.3 \pm 0.6^{* *}$ & $5.19 \pm 0.38^{* *}$ & $7.06 \pm 2.16^{* *}$ & $9.1 \pm 1.9^{* *}$ & $9.5 \pm 0.53^{* *}$ & $9.8 \pm 1.2^{* *}$ \\
L-NAME + captopril & $5.7 \pm 0.78^{\beta}$ & $6.42 \pm 0.53^{* * \beta}$ & $8.6 \pm 0.72^{* * \alpha}$ & $10.4 \pm 0.86^{* * \gamma}$ & $11.66 \pm 0.93^{* * \beta}$ & $12.04 \pm 1.77^{* * \beta}$ \\
L-NAME+ HEEO & $6.3 \pm 3.91^{\beta}$ & $7.95 \pm 6.64^{* \beta}$ & $9.8 \pm 10.81^{* * \alpha}$ & $12.6 \pm 14.8^{* * \beta}$ & $13.42 \pm 17.8^{* * \beta}$ & $14.9 \pm 17.45^{* * \beta}$ \\
\hline
\end{tabular}

Data represent the mean $\pm \mathrm{SEM}$ of each group. HEEO: hydroethanolic stem bark extract of $E$. oblongum. ${ }^{*} \mathrm{P}<0.05,{ }^{* *} \mathrm{P}<0.01$, significantly different compared to normal group. ${ }^{\alpha} \mathrm{P}<0.05$, significantly different compared to L-NAME (Nw Nitro-L- arginine methyl-ester) group. ${ }^{\beta} \mathrm{P}<0.01$, significantly different compared to L-NAME group.

\subsubsection{Food Consumption}

The effects of chronic administration of HEEO on food are showed in table 2. Treatment of rats during 28 days with LNAME has induced a significant $(\mathrm{P}<0.01)$ drop in food consumption compared to normal group. Treatment with captopril and plant extract blunted the decrease in food intake observed in hypertensive group. This effect was significantly marked with plant extract at the dose of $100 \mathrm{mg} / \mathrm{kg}$ during the treatment. So, the percentage of decrease of food intake at the fourth week.

Table 2. Effects of E. oblongum on food intake of L-NAME hypertensive rats after 4 weeks of treatment.

\begin{tabular}{lllllll}
\hline \multicolumn{1}{l}{ Food intake (g / 100g of body weight) } & \multicolumn{5}{l}{ day-25 } & day-28 \\
\hline Group & day-5 & day-10 & day-15 & day-20 & (15 \\
\hline Normal & $6.16 \pm 0.47$ & $9.06 \pm 0.45$ & $12.79 \pm 0.88$ & $14.16 \pm 0.55$ & $15.44 \pm 0.91$ & $16.59 \pm 0.26$ \\
L-NAME & $3.07 \pm 0.23^{* *}$ & $5.19 \pm 0.65^{* *}$ & $7.14 \pm 0.51^{* *}$ & $8.58 \pm 0.53^{* *}$ & $9.22 \pm 0.18^{* *}$ & $9.62 \pm 0.47^{* *}$ \\
L-NAME + captopril & $5.56 \pm 0.6$ & $6.42 \pm 0.8^{* *}$ & $8.03 \pm 0.66^{*}$ & $9.03 \pm 0.76^{*}$ & $10.66 \pm 0.34^{* *}$ & $11.47 \pm 0.22^{* *}$ \\
L-NAME+ HEEO & $5.41 \pm 0.33$ & $7.95 \pm 0.12^{\alpha}$ & $9.42 \pm 0.18^{*}$ & $10.43 \pm 0.49^{*}$ & $12.42 \pm 0.49^{* \alpha}$ & $13.73 \pm 0.42^{* \alpha}$ \\
\hline
\end{tabular}

Data represent the mean \pm SEM of each group; $g / 100 \mathrm{~g}$ of body weight: quantity taken in $\mathrm{g}$ per animal per week. HEEO: hydroethanolic stem bark extract of E. oblongum. ${ }^{*} \mathrm{P}<0.05,{ }^{* *} \mathrm{P}<0.01$, significantly different compared to normal group. ${ }^{\alpha} \mathrm{P}<0.05,{ }^{\beta} \mathrm{P}<0.01$ significantly different compared to L-NAME group (Nw Nitro-L- arginine methyl-ester).

\subsection{Antihypertensive Effects of E. Oblongum}

Subchronic oral administration of L-NAME $(40 \mathrm{mg} / \mathrm{kg}$ body weight /day) for 28 days resulted in a significant increase in mean systolic blood pressure (MSBP) by $46.94 \%$ and heart rate (HR) by $8.76 \%$ in L-NAME group as compared to normotensive rats (normal group). The hydroethanolic stem bark extract of E. oblongum at 100 $\mathrm{mg} / \mathrm{kg}$ body weight /day significantly blunted the increase in MSBP in LNHR but also reduced the MSBP level at a value below to that of normotensive rat (NTR). Comparable results were obtained with captotril ( $25 \mathrm{mg} / \mathrm{kg}$ body weight/day). Treatment with E. oblongum significantly blunted the increase in heart rate in LNHR at the dose, as well as captopril $25 \mathrm{mg} / \mathrm{kg}$ body weight/day (fig 1). 


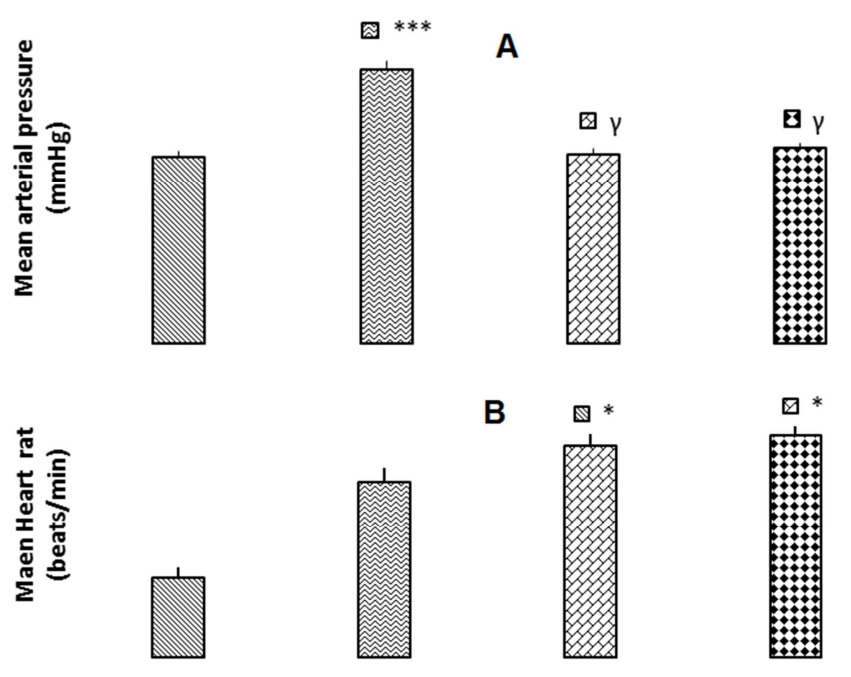

Figure 1. Effects of Eribroma oblongum on mean arterial pressure (A) and heart rate (B) of L-NAME hypertensive rats after 28 days of treatment.

Each bar represents the mean \pm SEM of group $* \mathrm{P}<0.05 ; * * \mathrm{P}<0.01$, significantly different compared to normal group; ${ }^{\gamma} \mathrm{P}<0.001$ significantly different compared to L-NAME group (Nw Nitro-L- arginine methyl-ester) group. L-NAME plus Captopril ( $25 \mathrm{mg} / \mathrm{kg}$ body weight/day); L-NAME plus Eribroma oblongum (100 mg/kg body weight/days) extract.

\subsection{Subchronic Effects of the Hydroethanolic Extract of Eribroma Oblongum on Lipid Profile}

Total cholesterol, HDL-cholesterol, LDL-cholesterol and triglycerides levels were significantly increased respectively by $34.43 \% \quad(\mathrm{P}<0.001), \quad 41.11 \% \quad(\mathrm{P}<0.001)$, by $19.24 \%$ $(\mathrm{P}<0.05)$ and by $64.50 \%(\mathrm{P}<0.001)$ in $\mathrm{LNHR}$ group as compared to normal group. HEEO significantly blunted the increase by $20.35 \%(\mathrm{P}<0.01)$ and by $38.85 \%(\mathrm{P}<0.001)$ respectively the level of total cholesterol or HDL-cholesterol as compared to normal group.

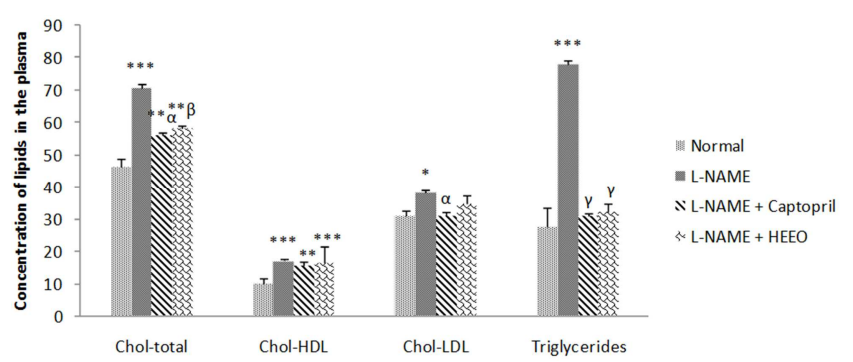

Figure 2. Effects of the hydroethanolic extract of Eribroma oblongum on lipid profil in L-NAME induced-hypertensive rats.

Data represents the mean \pm S.E.M. of each group; $\mathrm{n}=5$ number of animals in each group; $* \mathrm{P}<0.05,{ }^{*} \mathrm{P}<0.01$ and $* * * \mathrm{P}<0.001$ significantly different compared to the normal group. ${ }^{\alpha} \mathrm{P}<0.05,{ }^{\beta} \mathrm{P}<0.01$ and ${ }^{\gamma} \mathrm{P}<0.001$ significantly different compared to L-NAME ( $\mathrm{N}_{\mathrm{W}}$-Nitro-L-Arginine Methyl Ester) group. TC: total Cholesterol; LDL-C: Low Density Lipoproteins Cholesterol; HDLC: High Density Lipoproteins-Cholesterol.

\subsection{Effect of Hydroethanolic Extract of the Bark Stem of E. Oblongum on Cardiovascular Risk}

After 4 weeks of gavage with a solution of L-NAME 40 $\mathrm{mg} / \mathrm{kg}$ body weight /day, in normotensive rats, we found that the hydroethanolic stem bark extract of E. oblongum at a dose of $100 \mathrm{mg} / \mathrm{kg}$ body weight/day administered concomitantly decreased the risk of developing atherosclerosis of $23.27 \%$ or $31.16 \%$ (table 3 ).

Table 3. Effects of the hydroethanolic extract of Eribroma oblongum on atherogenic Indexe in L-NAME induced-hypertensive rats.

\begin{tabular}{llll}
\hline Group & Normal & L-NAME 40 mg/kg Pc & L-NAME 40 mg/kg Pc + \\
\cline { 3 - 4 } & & Captopril 25 mg/kg Pc & HEEO. 100 mg/kg Pc \\
\hline Atherogenic Indexe 1 TC/HDL-C & 4.64 & 4.16 & 3.58 \\
*Protection(\%) 1 & - & - & 22.64 \\
Atherogenic Indexe 2 LDL-C/HDL-C & 3.08 & 2.25 & 1.98 \\
*Protection(\%) 2 & - & - & 5.56 \\
\hline
\end{tabular}

HEEO: hydroethanolic stem bark extract of Eribroma oblongum; L-NAME: $\mathrm{N}_{\mathrm{W}}$-Nitro-L-Arginine Methyl Ester; TC: total Cholesterol; LDL-C: Low Density Lipoproteins Cholesterol; HDL-C: High Density Lipoproteins-Cholesterol.

\subsection{Effects of Hydroethanolic Extract of E. oblongum on Liver and Kidney Function}

Levels of ALT and AST increased significantly from $40.44 \%(\mathrm{P}<0.001)$ and $44.71 \%(\mathrm{P}<0.001)$ compared to the normal group. The hydroethanolic stem bark extract of $E$. oblongum caused a significant increase in ALT levels 26.92\% ( $\mathrm{P}<0.01)$ compared to the control group and $18.50 \%$ ( $\mathrm{P}$ $<0.001)$ compared to the group treated with L-NAME and a significant decline in AST 28.95\% ( $\mathrm{P}<0.01)$ compared to group rats rendered hypertensive by L-NAME (table 4).

Table 4. Effects hydroethanolic extract of Eribroma oblongum on liver and kidney functions.

\begin{tabular}{llll}
\hline \multirow{2}{*}{ Group } & Normal & L-NAME 40mg/kg Pc & L-NAME 40mg/kg Pc + \\
\cline { 3 - 4 } & & & Captopril 25mg/kg Pc \\
\hline ALAT (U/L) & $27.77 \pm 1.02$ & $46.63 \pm 10^{* * *}$ & $29.36 \pm 2.16^{\beta}$ \\
\hline ASAT (U/L) & $43.27 \pm 4.70$ & $78.27 \pm 4.13 * * *$ & $50.72 \pm 2.22 * *$ \\
\hline ASAT/ALAT & 1.55 & 1.67 & 1.72 \\
Creatinine (mg/dL) & $1.47 \pm 0.28$ & $1.10 \pm 0.26$ & $1.81 \pm 0.28$ \\
\hline
\end{tabular}

Data represent the mean $\pm \mathrm{SEM}$ of each group. $\mathrm{n}=5$ : number of animals in each group; $* * \mathrm{P}<0.01$ and $* * * \mathrm{P}<0.001$ significantly different compared to the normal group. ${ }^{\alpha} \mathrm{P}<0.05$ and ${ }^{\beta} \mathrm{P}<0.01$ significantly different compared to L-NAME ( $\mathrm{N}_{\mathrm{W}}$-Nitro-L-Arginine Methyl Ester) group. ALAT: Alanine animotransferase; ASAT: Aspartate animotransferase; HEEO: Hydroethanolic extract of Eribroma oblongum. 


\subsection{Effect of E. oblongum on Oxidative Stress Biomarkers}

The concentration of nitrite $\left(\mathrm{NO}_{2}^{-}\right)$decrease significantly in heart by $49.83 \%(\mathrm{P}<0.05)$, liver by $64.43 \%(\mathrm{P}<0.001)$ and kidney by $68.30 \%(\mathrm{P}<0.05)$ in LNHR as compared to the normal group. The HEEO prevented the deleterious effects of LNHR in the tissues. It decreased significantly by $61.45 \%$ $(\mathrm{P}<0.01)$ and $43.46 \%(\mathrm{P}<0.05)$ the concentration of nitrite in aorta and liver respectively compared to the normal group Table 4 shows that reduced glutathione (GSH) levels were significantly decreased in aorta by $57.27 \%(\mathrm{P}<0.05)$, heart by $65.51 \%(\mathrm{P}<0.01)$ and liver by $80.64 \%(\mathrm{P}<0.001)$ of $\mathrm{LNHR}$ compared to normal group. Likewise, the extract $(100 \mathrm{mg} / \mathrm{kg}$ body weight/day) like captopril significantly prevented the decrease in GSH levels. Group of LNHR exhibited a significant decrease in aorta by $56.06 \%(\mathrm{P}<0.05)$, liver by $74.19 \%(\mathrm{P}<0.001)$ and kidney by $26.24 \%(\mathrm{P}<0.01) \mathrm{GSH}$ activity as compared to normal group (table 4) whereas GSH significantly increased in the liver by $18.94 \%(\mathrm{P}<0.001)$ as compared to LNHR group. Conversely, L-NAME-induced hypertension was associated with an increase in aortic SOD activity, the values (U/mg proteins) rising from $25.10 \pm 2.05$ in normal group to $42.94 \% \quad(\mathrm{P}<0.01)$, in LNHR group.
Treatment with the plant extract prevented the increase in SOD activity in the aorta, heart, liver and kidneys from LNHR group. Captopril treatment also reduced the increase in aorta SOD activity and significantly blunted the decrease in SOD activity in the heart, liver and kidney (table 5).

The catalase activity was decreased significantly in aorta by $85.94 \%(\mathrm{P}<0.01)$, heart by $70.53 \%(\mathrm{P}<0.01)$, liver by $70.56 \%(\mathrm{P}<0.001)$ and kidney by $74.21 \%(\mathrm{P}<0.001)$ as compared to normal group. The HEEO significantly prevented the deleterious effects of LNHR group in the tissues. It increased catalase activity in kidney by $44.34 \%$ $(\mathrm{P}<0.01)$ as compared to the normal group and $18.13 \%$ $(\mathrm{P}<0.05)$ or $66.97 \%(\mathrm{P}<0.001)$ respectively in heart and liver as compared to LNHR group (table 5).

MDA levels were significantly $\mathrm{P}<0.001$ higher in aorta by $42.02 \%$, liver by $41.56 \%$, and kidney by $43.11 \%$ tissues of LNAME treated rats as compared to normal group. Treatment with E. oblongum $(100 \mathrm{mg} / \mathrm{kg} /$ day $)$ for 28 days significantly $\mathrm{P}<0.001$ prevented the rise in tissue MDA levels in aorta by $55.05 \%$, liver by $55.60 \%$ and kidney by $44.57 \%$ as compared to LNHR group. The same effect was observed with captopril (table 5).

Table 5. Effects of hydroethanolic extract of Eribroma oblongum on oxidative stress markers.

\begin{tabular}{|c|c|c|c|c|c|}
\hline & & \multirow{2}{*}{ Normal } & \multirow{2}{*}{$\begin{array}{l}\text { L-NAME } \\
40 \mathrm{mg} / \mathrm{kg} \mathrm{Pc}\end{array}$} & \multicolumn{2}{|l|}{ L-NAME $40 \mathrm{mg} / \mathrm{kg} \mathrm{Pc}+$} \\
\hline & & & & Captotril $25 \mathrm{mg} / \mathrm{kg} \mathrm{Pc}$ & HEEO $100 \mathrm{mg} / \mathrm{kg} \mathrm{Pc}$ \\
\hline \multirow{4}{*}{$\begin{array}{l}\mathrm{NO}_{2}^{-} \\
(\mu \mathrm{M} / \mathrm{mg} \text { of protein })\end{array}$} & Aorta & $20.94 \pm 2.10$ & $10.14 \pm 0.04$ & $27.57 \pm 3.92^{\beta}$ & $26.31 \pm 3.65^{\beta}$ \\
\hline & Heart & $30 \pm 5.90$ & $15.05 \pm 0.32 *$ & $20.79 \pm 0.61$ & $17.77 \pm 1.18$ \\
\hline & Liver & $35.82 \pm 6.09$ & $12.74 \pm 0.37 * * *$ & $22.08 \pm 2.04 *$ & $20.25 \pm 1.03 *$ \\
\hline & Kidneys & $50.19 \pm 12.4$ & $15.91 \pm 0.53 *$ & $37.17 \pm 4.4$ & $26.57 \pm 2.03$ \\
\hline \multirow{4}{*}{$\begin{array}{l}\text { Gluthatione } \\
(\mu \mathrm{mol} / \mathrm{L})\end{array}$} & Aorta & $3.3 \pm 0.63$ & $1.41 \pm 0.17^{*}$ & $4.14 \pm 0.45^{\beta}$ & $1.45 \pm 0.05 *$ \\
\hline & Heart & $2.61 \pm 0.07$ & $0.90 \pm 0.04 * *$ & $3.20 \pm 0.43^{\gamma}$ & $3.22 \pm 0.4^{\gamma}$ \\
\hline & Liver & $2.48 \pm 0.13$ & $0.48 \pm 0.05 * * *$ & $0.82 \pm 0.04 * * * \alpha$ & $0.64 \pm 0.06^{* * *}$ \\
\hline & Kidneys & $1.41 \pm 0.11$ & $1.03 \pm 0.1$ & $1.81 \pm 0.15^{\gamma}$ & $0.77 \pm 0.06^{* *}$ \\
\hline \multirow{4}{*}{$\begin{array}{l}\text { SOD } \\
\text { (U/mg of protein) }\end{array}$} & Aorta & $25.10 \pm 2.05$ & $14.32 \pm 0.77 * *$ & $34.52 \pm 2.24 * * \gamma$ & $15.89 \pm 1.49 * *$ \\
\hline & Heart & $50.54 \pm 6.48$ & $25.16 \pm 1.09 *$ & $35.66 \pm 1.07$ & $38.15 \pm 8.79$ \\
\hline & Liver & $43.68 \pm 1.15$ & $25.69 \pm 2.71 * * *$ & $34.93 \pm 1.87$ & $33.82 \pm 3.75$ \\
\hline & Kidneys & $36.96 \pm 5.16$ & $21.45 \pm 0.74 * *$ & $31.62 \pm 0.8$ & $33.53 \pm 2.02^{\alpha}$ \\
\hline \multirow{4}{*}{$\begin{array}{l}\text { Catalase } \\
\text { (U/mg of protein) }\end{array}$} & Aorta & $50.03 \pm 12.8$ & $7.03 \pm 1.33 * *$ & $22.92 \pm 1.09$ & $31.06 \pm 5.28$ \\
\hline & Heart & $40.08 \pm 7.41$ & $11.81 \pm 0.43 * *$ & $37.53 \pm 4.1^{\beta}$ & $32.81 \pm 1.22^{\alpha}$ \\
\hline & Liver & $72.13 \pm 3.91$ & $21.23 \pm 3.91 * * *$ & $52.39 \pm 8.84^{\beta}$ & $64.28 \pm 2.53^{\gamma}$ \\
\hline & Kidneys & $65.82 \pm 6.93$ & $16.97 \pm 3.66^{* * *}$ & $49.96 \pm 5.29^{\beta}$ & $36.63 \pm 2.42 * *$ \\
\hline \multirow{4}{*}{$\begin{array}{l}\text { Malondialdehyde } \\
\text { ( } \mu \mathrm{mol} / \mathrm{mg} \text { of protein) }\end{array}$} & Aorta & $44.9 \pm 0.68$ & $77.45 \pm 0.53 * * *$ & $65.76 \pm 7.81 *$ & $34.81 \pm 3.02^{\gamma}$ \\
\hline & Heart & $22.60 \pm 1.76$ & $38.69 \pm 9.27$ & $28.31 \pm 2.37$ & $24.36 \pm 0.69$ \\
\hline & Liver & $15.08 \pm 0.6$ & $35.34 \pm 2.74 * * *$ & $29.94 \pm 3.93 * *$ & $15.69 \pm 1.01^{\gamma}$ \\
\hline & Kidneys & $20.65 \pm 0.77$ & $36.30 \pm 2.2 * * *$ & $29.31 \pm 0.77 * * a$ & $20.12 \pm 1.56^{\gamma}$ \\
\hline
\end{tabular}

Data represent the mean \pm SEM of group; $\mathrm{n}=5$ : number of animals in each group. $\mathrm{NO}_{2}^{-}$: nitrite; SOD: super oxide dismutase; HEEO: hydroethonolic stem bark extract of Eribroma oblongum. ${ }^{*} \mathrm{P}<0.05,{ }^{* *} \mathrm{P}<0.01$ significantly different compared to normal group and, ${ }^{\alpha} \mathrm{P}<0.05,{ }^{\beta} \mathrm{P}<0.01,{ }^{\gamma} \mathrm{P}<0.001$; significantly different compared to L-NAME ( $\mathrm{N}_{\mathrm{W}}$-Nitro-L-Arginine Methyl Ester) group

\section{Discussion}

This study aimed to evaluate the antihypertensive effect of hydroethanolic stem bark extract of E. oblongum on LNAME-induced hypertensive rats. the administration of the solution with L-NAME $40 \mathrm{mg} / \mathrm{kg}$ bw/day is a non selective inhibitor of NO synthase [16, 17], during 28 days leads to the increase significantly $\mathrm{P}<0.001$ of mean systolic arterial blood pressure (MSBP) by $46.94 \%$ in L-NAME group as compared to normal group. HEEO $100 \mathrm{mg} / \mathrm{kg}$ bw/day prevented significantly $\mathrm{P}<0.001$ hypertension by $28.39 \%$ in rats simultaneously treated with L-NAME, in comparison to LNAME group (fig. $1 \mathrm{~A}$ ). The blocking oxide synthase nitrite by L-NAME resulted dyslipidemia, which play an important 
role in the pathogenesis of hypertension [18]. Hypertension and hyperlipidemia are two cardiovascular risk factors. Thus to reduce the cardiovascular risk, it is important to qualitative and quantitative change one or more parameters of plasma lipids [19]. The observed dyslipidemia was characterized by hypertriglyceridemia, hypercholesterolemia, elevated HDLcholesterol and LDL-cholesterol. Dyslipidemia observed in the group of hypertensive rats made was prevented by the ethanolic extract and captopril, which improved the lipid profile by increasing the production of nitrite oxide. These results clearly showed that the hydroethanolic extract of $E$. oblongum has hypotriglycéridémiantes and cholesterollowering properties on atherogenic risk. The pharmacological activity of this extract could be explained by the presence of phytochemical constituents such as flavonoids and saponins in the plant. These bioactive phytomolecules are known to possess vasorelaxant activity, antihypertensive and antihyperlipidémiantes [20]. Chronic administration of LNAME rats is a source of hepatotoxicity, characterized by, among other malfunction in serum transaminase levels. The transaminases (ALT, AST) are well known enzymes as good indicators of liver function and as possible toxicity markers [21]. ALT and AST are important enzymes produced by the liver and serum levels of these enzymes are widely used as biomarkers of liver health [22]. Regarding the activity of transaminases, significant increase or decrease in transaminase activity in the group of rats made hypertensive with L-NAME may reflect liver damage. Co-administration of L-NAME and the extract allowed to significantly increase serum transaminases compared to rats made hypertensive group, suggesting that the hydroethanolic extract $E$. oblongum protect the liver toxicity due to L-NAME. LNAME is an L-arginine analog which blocks nitric oxide production in endothelial cells resulting in elevation of blood pressure $[23 ; 24]$. HEEO and captopril significantly prevented development of hypertension in rats. Captopril, an angiotensin converting enzyme (ACE) inhibitor blocks the production of angiotensin II and reduces blood pressure [25]. HEEO could prevent hypertension by NO/GMPC releasing. However, the possible hypotensive effect of the extract through ACE system could be explored. Indeed, the nitrite oxide (NO) plays a critical role in the maintenance of basal vascular tone. Factors other than the inhibition of NO may be involved in the development of hypertension induced by LNAME, such as the activation of vasoconstrictor systems like the renin-angiotensin system, endothelin or the sympathetic nervous system $[26 ; 27]$. The mechanisms involved in this beneficial effect may involve inhibiting the sympathetic system as suggested by the results of intravenous study. However, other mechanisms may also be involved, including the reduction of oxidative stress. During installation of hyperlipidemia, cell membranes and extracellular matrix may change their lipid composition and thus be more capable of generating free radicals. Oxidative stress alters lipids creating a disturbance of self-generation cycle of free radicals and protein modification [28]. In addition, patients with hypertension, the decrease in antioxidant defenses is well documented [29]. Our results showed that in this model of hypertension several oxidative stress markers are altered. Reduced glutathione (GSH) is an endogenous antioxidant most abandant in eukaryotic cells that interacts with activated oxygen species, thereby preventing the oxidation of organic substrates (proteins, DNA, fatty acids). GSH is also a scavenger of superoxide radicals and protects the thiol groups of proteins against oxidation [30]. Our results showed a general decrease in the level of glutathione reduced in aorta, heart, liver and kidneys of rats made hypertensive by LNAME. The determination of the specific activity of superoxide dismutase (SOD), an enzyme that catalyzes the dismutation of the superoxide anion $\left(\mathrm{O}_{2}{ }^{-}\right)$into water and hydrogen peroxide [31] shows a decrease of activity SOD in the aorta, heart and kidney of hypertensive rats. The increase in SOD activity has been reported in the aorta of rats [32] and would be secondary to the increased production of $\mathrm{O}_{2}^{-}$. Our results suggest that in this model the aorta, heart, liver and kidneys would be affected by oxidative stress. The hydroethanolic stem bark extract of E. oblongum reduced the nitrite levels around the normal value at the aorta. These results suggest that the extract has a protective role against the endothelial dysfunction induced by L-NAME. Malondialdehyde (MDA) is used as an index of lipid peroxidation resulting from the reaction of active oxygen species with the membrane fatty acids [33]. In our study, it was observed in hypertensive rats made a significant increase in MDA levels especially in the liver. The hydroethanolic stem bark extract of E. oblongum has had a beneficial effect on tissue parameters of oxidative stress; namely a reduction rate of SOD, catalase and MDA and nitrites increase the rate. These results suggest that the extract of E. oblongum would be capable of preventing lipid peroxidation induced by LNAME and increase vasodilation of vessels.

\section{Conclusion}

In conclusion, present study showed that the oral administration of hydroethanolic stem bark extract of Eribroma oblongum possesses antioxidant activity, protective effects on the vessels by improving the NO bioavailability. This helps in prevention of hypertension induced by LNAME. Overall data justified the empirical uses of this plant in the treatment of arterial hypertension associated with NO deficiency.

\section{References}

[1] Beevers G, Lip GY, O'Brien E: ABC of hypertension: The pathophysiology of hypertension. BMJ (Clin Res ed) 2001, 322(7291): 912-916.

[2] Razny U, Kiec-Wilk B, Wator L, Polus A, Dyduch G, Solnica B, Malecki M, Tomaszewska R, Cooke JP, Dembinska-Kiec A: Increased nitric oxide availability attenuates high fat diet metabolic alterations and gene expression associated with insulin resistance. Cardiovasc Diabetol 2011; 10: 68. 
[3] WHO. World health report. Reducing risks, promoting healthy life, World Health Organization, Geneva, Switzerland 2002; 714 .

[4] Whitworth, JA. World Health Organization, International Society of Hypertension Writing Group. World Heath Organization (WHO)/InternationalSociety of Hypertension (ISH) statement on management of hypertension. Journal of Hypertension 2003; 11: 1983-1992.

[5] OMS (Organisation Mondiale de la Santé). Médicine traditionnelle. Aide mémoire No 134. Geneva: WHO; 2003; 4.

[6] Tsague MV, Fokunang NC, Ngameni B, Tembe-fokunang EA, Guedje NM, Ngo Lemba Tom E, Atogho-Tiedeu B, Zintchem RF, Mecthi Dongmo M, Ngoupayo J, Sokeng S, Dzeufiet Djomeni, Oben JE, Dimo T, Ze Minkande J and Ngadjui Tchaleu B. Pre-clinical evaluation of the hypotensive and anti atherogenic activity of hydroethanolic extract of Eribroma oblongum (Malvaceae) stem bark on wistar rats models. British Journal of Pharmaceutical research. 2015; 5(1): 1-14

[7] EEC: Council Directive 86/609/EEC of 24 November 1986 on the approximation of laws, regulations and administrative provisions of the Member States regarding the protection of animals used for experimental and other scientific purposes. Official Journal of the European Communities1986; L358:1-29.

[8] Dimo T, Nguelefack TB, Tan PV, Yewah MP, Dongo E, Rakotonirina SV, Kamanyi A and Bopelet M. Possible mechanisms of action of the neutral extract from Biden spilosa L. leaves on the cardiovascular system of anesthetized rats. Phytother Res 2003; 17: 1135-1139.

[9] Ester Ngo Lemba Tom, Céline Demougeot, Orelien Bopda Mtopi, Théophile Dimo, Paul Désiré Dzeufiet Djomeni, Danielle Claude Bilanda, Corinne Girard, Alain Berthelot. Journal of etnopharmacology 133 (2011); 828-833.

[10] Misra H, Fridovich I. The role of superoxide anion in the autoxidation of epinephrine to adrenochrome and a simple assay for superoxide dismutase.Journal of Biological Chemistry 1972; 247:3170-5.

[11] Sinha AK. Colorimetric assay of catalase. Analytical Biochemistry 1972; 47:389-94.

[12] Ellman GL. Tissue sulfhydryl group. Archives of Biochemistry and Biophysics 1959; 82:70-7.

[13] Ikeda U., M. Takahashi and K. Shimada. C-reactive protein directly inhibits nitric oxide production by cytokinestimulated vascular smooth muscle cells. J. Cardiovasc. Pharmacol., 2003; 42: 607-611.

[14] Wilbur KM, Bergheim F, Shapiro OW. Determination of lipid peroxidation. Archives of Biochemistry 1949; 24: 305-10.

[15] Friedewald WT, Levy RI, Fredrickson DS. Estimation of the concentration of low-density lipoprotein cholesterol in plasma, without use of the preparative ultracentrifuge. Clinical Chemistry 1972; 18:499-502.

[16] Corvol P. L'endothélium, plaque tournante de la vasomotricité et de la trophicité de la paroi artérielle. Médecine/Sciences. 1993; 9(10):1031-1033.

[17] Badyal DK, Lata H, Dadhich AP. Animal models of hypertension and effect of drugs. Indien Journal of Pharmacology, 35:349-362.ms in cardiology. 2003; 28: 137155.
[18] Saravanakumar M, Raja B. Effect of veratric acid on the cardiovascular risk of L-NAME-induced hypertensive rats. Journal of Cardiovascular Pharmacology. 2012; 59: 553-562.

[19] Deshmukh M, Lee HW, McFarlane SI, Whaley-Connell A. Antihypertensive medications and their effects on lipid metabolism. Curr Diab Rep. 2008; 3: 24-220.

[20] Han LK, Zheng YN, Xu BJ, Okuda H, Kimura Y. Saponins from platycodi radix ameliorate high fat diet-induced obesity in mice. J Nutr. 2002; 132(8): 2241-2245.

[21] Hilaly J, El Israili ZH, Lyoussi B. Acute and chronic toxicological studies of Ajuga ivain experimental animals. Journal of Ethnopharmacology. 2004; 91: 43-50.

[22] Kudo T, Tamagawa T, Shibata S. Effect of chronic ethanol exposure on the liver of Clock-mutant mice. J Circadian Rhythms 2009; 10.1186/1740-3391-7-4.

[23] Tsuchiya K, Shuhei T, Keisuke I, Shinji A, Yasumasa I, Yoshitaka K, et al. Dietary nitrite ameliorates renal injury in 1NAME-induced hypertensiverats. Nitric Oxide 2009;22:98103.

[24] Kang DG, Hur TY, Lee GM, Oh H, Kwon TO, Sohn EJ, et al. Effects of Cudrania tricuspidata water extract on blood pressure and renal functions in NO-dependent hypertension. Life Sciences 2002;70:2599-609.

[25] Miguel-Carrasco JL, Monserrat MT, Mate A, Vázquez CM. Comparative effects of captopril and l-carnitine on blood pressure and antioxidant enzyme gene expression in the heart of spontaneously hypertensive rats. European Journal of Pharmacology 2010;632:65-72.

[26] Jover B, Mimran A. Nitric oxid inhibition and renal alterations. J. cardiovasc Pharmacol.2001; 38(2):65-70.

[27] José Marcos Girardi, Rogério Estevan Farias, Ana Paula Ferreira, and Nádia Rezende Barbosa Raposo. Rosuvastatin prevents proteinuria and renal inflammation in nitric oxidedeficient rats. Clinics (Sao Paulo). 2011; 66(8): 1457-1462.

[28] Scheuer H, Gwinner W, Hohbach J, Gröne EF, Brandes RP, Malle E, Olbricht CJ, Walli AK, Gröne HJ. Oxidant stress in hyperlipidemia induced renal damage. Am J Physiol Renal Physiol. 2000; 278: F63-F74.

[29] Rodrigo R, Prat H, Passalacqua W, Araya J, Guichard C, Bachlet JP. Relationship between Oxidative Stress and Essential Hypertension. Hypertension Research. 2007; 30 : 1159-1167.

[30] Stein HJ, Esplugues J, Whittle BJR. Direct cytotoxic effect of oxygen free radicals on the gastric mucosa. Surgery. 1989; 106: 318-24.

[31] Faraci FM, Didion SP. Vascular protection: superoxide dismutase isoforms in the vessel wall. Artheriosclerosis Thrombose and Vascular Biology. 2004; 24: 1367-1373.

[32] El Midaoui A, de Champlain J. Prevention of hypertension, insulin resistance, and oxidative stress by $\alpha$-Lipoic acid. Hypertension. 2002; 39: 303-307.

[33] Nayeemunisa, Kumda MR. Cardioprotective effects of Cichorium intybus in ageing myocardium of albino rats. Current Science. 2003; 84: 94-943. 